\title{
Associations of intake of antioxidant vitamins and fatty acids with asthma in pre-school children
}

\author{
Kozue Nakamura ${ }^{1, *}$, Keiko Wada ${ }^{1}$, Yukari Sahashi ${ }^{1}$, Yuya Tamai ${ }^{1}$, Michiko Tsuji ${ }^{1}$, \\ Kaori Watanabe ${ }^{2}$, Sakiko Ohtsuchi ${ }^{2}$, Kyoko Ando ${ }^{2}$ and Chisato Nagata ${ }^{1}$ \\ 'Department of Epidemiology and Preventive Medicine, Gifu University Graduate School of Medicine, \\ 1-1 Yanagido Gifu 501-1 194, Japan: ${ }^{2}$ Department of Life and Culture, Aichi Bunkyo Women's College, \\ Aichi, Japan
}

Submitted 1 March 2012: Final revision received 15 August 2012: Accepted 31 August 2012: First published online 1 0ctober 2012

\begin{abstract}
Objective: Increasing childhood asthma rates may be due to changing dietary lifestyle. We investigated the association of dietary intake of antioxidant vitamins and fatty acids with asthma in Japanese pre-school children.

Design: Cross-sectional study.

Setting: School-based survey on lifestyle/diet and health status in children in Japan.

Subjects: Parents of 452 children aged 3-6 years completed a questionnaire on the children's and parents' lifestyle and demographics. Children were classified into asthma cases and non-asthma cases in accordance with the ATS-DLD (American Thoracic Society and Division of Lung Diseases of the National Heart, Lung, and Blood Institute) questionnaire. Children's diet was assessed using a $3 \mathrm{~d}$ dietary record completed by parents. Children's age, sex, BMI, history of food allergy, maternal age, parental history of allergy, maternal education, family size and second-hand smoking were included as covariates. Logistic regression models were used to examine the association between children's diet and asthma.

Results: Compared with children with the lowest intake tertile for vitamin $\mathrm{C}$ and vitamin $\mathrm{E}$, those in the highest were significantly inversely associated with asthma; adjusted OR (95\% CI) were $0.35(0 \cdot 14,0.88)$ and $0.32(0 \cdot 12,0.85)$, respectively. A statistically significant trend was also observed. Fruit intake showed an inverse but insignificant association with asthma. There were no associations of any type of fatty acids with asthma.

Conclusions: These data suggest that children with high intakes of vitamins $\mathrm{C}$ and E may be associated with a reduced prevalence of asthma.
\end{abstract}

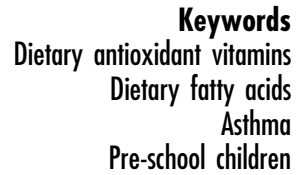

In the past three decades, childhood asthma has become the most common chronic disease among children in developed and developing countries including Japan ${ }^{(1,2)}$. This trend towards an increase in asthma prevalence has been so rapid that it is less likely to be explained by genetic alterations than environmental factors ${ }^{(2,3)}$. Among many environmental factors, changes in diet have been suggested to be responsible for the increase in allergies ${ }^{(3)}$. A shift towards Western society in East Germany after reunification in 1990 caused a drastic change in living conditions and subsequently an increase in the occurrence of asthma in a short time ${ }^{(4)}$. The increase in margarine intake observed in the former East Germany after reunification is a suspected factor in the increase in allergies ${ }^{(5)}$. A diet low in SFA and high in $n-6$ PUFA has been recommended to reduce the risk of $\mathrm{CHD}$. $\mathrm{PGE}_{2}$ inhibits interferon- $\gamma$ and reduces $\operatorname{IgE}$ production, which leads to the development of allergy ${ }^{(3,6)}$.
$\mathrm{PGE}_{2}$ is produced from arachidonic acid, which is produced from $n-6$ fatty acids ${ }^{(6)}$. Black and Sharpe suggested that a high $n-6$ PUFA diet may increase $\mathrm{PGE}_{2}$ synthesis and cause inflammation, which may have led to the increase in asthma $^{(5-7)}$. The increase in asthma may also be attributed to a decrease in the consumption of fish and products containing $n$-3 PUFA, EPA and DHA ${ }^{(6)}$. These fatty acids are expected to inhibit the production of $\mathrm{PGE}_{2}$ and protect against asthma $^{(4)}$.

Many features of asthma are induced by the oxidantcaused release of pro-inflammatory mediators ${ }^{(8)}$. Therefore, it is postulated that a lower dietary intake of antioxidants induced by dietary change leads to the attenuation of antioxidant defence in the lung and enhances susceptibility to airway inflammation and asthma ${ }^{(3,9)}$. Epidemiological studies have investigated the relationship of dietary antioxidants and fat intake to asthma; however, indisputable 
results have not been obtained ${ }^{(10-26)}$. So far, only one systematic review on diet and childhood asthma has been done, which also concluded that the evidence for the link between vitamins and fat and asthma was insufficient ${ }^{(27)}$. In the present study, to investigate whether the consumption of dietary antioxidant vitamins and fatty acids is associated with the status of asthma, we conducted a cross-sectional study among Japanese pre-school children.

\section{Methods}

\section{Study population}

The study population comprised pre-school children aged 3-6 years, all of whom attended pre-schools in Aichi Prefecture, Japan. A total of 533 children (266 boys and 267 girls) were recruited for the present study from October to November 2006. Through the children's teachers, we distributed a parent- or guardian-administered questionnaire regarding the children's and parents' lifestyle factors and health status. After excluding those whose parents declined to participate or returned inaccurate replies to the questionnaire, 459 children ( 243 boys and 216 girls) participated in the study; the participation rate was $86 \cdot 1 \%$. Of these participants, seven children were excluded because they left more than $80 \%$ of the questionnaire and diet record blank. Finally, the data for 452 children were included in the analyses because their parents or guardians had provided sufficient information on the children's asthma, diet and related factors.

\section{Measurements}

The distributed questionnaire included questions about the demographics of the parents and children, maternal education level, parental history of allergies, children's growth and allergy history, children's diet, second-hand smoking and exposure to allergens. We identified cases of asthma based on responses to questions from the ATS-DLD (American Thoracic Society and Division of Lung Diseases of the National Heart, Lung, and Blood Institute) questionnaire for children ${ }^{(28)}$. Three questions were included: (i) 'Has your child ever had an attack of wheezing that has caused him/her to be short of breath?'; (ii) 'Has your child had two or more episodes of the attack?'; and (iii) 'Has a doctor ever said that your child had asthma?'. When all replies to these questions were affirmative, the children were defined as asthma cases.

\section{Dietary assessment}

The children's dietary habits were evaluated using a $3 \mathrm{~d}$ dietary record completed by parents or guardians ${ }^{(29)}$. In order to estimate the children's common dietary habits, we requested that the parents or guardians record the children's diet from two successive weekdays and one weekend day. We sent them a detailed manual for recording the food intakes of their children. According to the manual, parents or guardians quantified the amount and wrote details of foods, drinks and dishes consumed by children using standard portions and units. Our participants usually had a school-provided lunch every weekday. We obtained menus (containing the supply quantity and kind of food) in advance of the study date. To know the actual intake of foods at lunch, dietitians applied visual estimation to record the individual quantities of uneaten meals at lunchtime. In addition, use of supplementation was also recorded in a $3 \mathrm{~d}$ dietary record. Each child's intake of total fat, SFA, PUFA, MUFA, $n-3$ PUFA, $n$-6 PUFA, linoleic acid, $\alpha$-linolenic acid, EPA, DHA, arachidonic acid, retinol, $\alpha$-carotene, $\beta$-carotene, cryptoxanthin, vitamin $\mathrm{C}$, vitamin $\mathrm{E}$, fruit, vegetables, fish and meat was calculated using the Japanese Standard Tables of Food Composition, 5th revised and enlarged edition, published by the Science and Technology Agency of Japan. Intake of dietary vitamin A was presented as retinol equivalents $(\mu \mathrm{g})$ and calculated by adding 1 retinol, 1/12 $\beta$-carotene and $1 / 24 \alpha$-carotene to $1 / 24$ cryptoxanthin. Intake of fatty acids was evaluated according to the substituted fatty acid composition table published by Sasaki et $a l^{(30)}$. Informed consent was obtained from parents or guardians of all participants before the study. The study was approved by the ethics board of the Gifu University Graduate School of Medicine.

\section{Statistical metbod}

To evaluate the relationships between asthma and the intake of selected foods or nutrients, we computed OR and their 95\% CI using a logistic regression model. Nutrient intake from diet plus supplements was adjusted for individual total energy intake after log-transformation by using the residual method proposed by Willett ${ }^{(31)}$. The energy-adjusted amounts of foods or nutrients were classified into tertiles based on the distribution of all study participants. The OR and their 95\% CI for asthma in the middle and highest categories of dietary intake were calculated compared with the lowest one. In addition to crude and age- and sex-adjusted OR, we calculated multivariate-adjusted OR and 95\% CI after controlling for the known or possible confounding factors. These factors included: the children's BMI, type of feeding during infancy (breast-fed only, formula-fed only, or breast- and formula-fed), personal history of food allergy, the mother's age, maternal or paternal history of allergy, maternal education level, the number of siblings and household smoking. The trend of association was tested on continuous values of each nutrient or food group by a logistic regression analysis. The children with a history of food allergy in early infancy may have changed their habitual diet. Some children may have kept away from certain foods because of symptoms due to asthma or other allergic disease. We repeated the analysis after excluding children with a history of food allergy. All statistical analyses were performed using the SAS 
Table 1 Basic characteristics of the 452 Japanese pre-school children

\begin{tabular}{|c|c|c|}
\hline Characteristic & $n$ or Mean & $\%$ or SD \\
\hline Boys $(n, \%)$ & 240 & $53 \cdot 1$ \\
\hline \multicolumn{3}{|l|}{ Age (years), $(n, \%)$} \\
\hline$\geq 3$ to $<4$ & 143 & $31 \cdot 6$ \\
\hline$\geq 4$ to $<5$ & 132 & $29 \cdot 2$ \\
\hline$\geq 5$ to $\leq 6$ & 177 & $39 \cdot 2$ \\
\hline Height $(\mathrm{cm})$ & $106 \cdot 7$ & $7 \cdot 2$ \\
\hline Weight (kg) & $17 \cdot 4$ & $2 \cdot 6$ \\
\hline BMI $\left(\mathrm{kg} / \mathrm{m}^{2}\right)$ & $15 \cdot 3$ & $1 \cdot 4$ \\
\hline History of food allergy $(n, \%)$ & 55 & $12 \cdot 0$ \\
\hline \multicolumn{3}{|l|}{ Number of siblings $(n, \%)$} \\
\hline 0 & 101 & $22 \cdot 5$ \\
\hline 1 & 283 & $53 \cdot 6$ \\
\hline$\geq 2$ & 64 & $14 \cdot 2$ \\
\hline \multicolumn{3}{|l|}{ Feeding in infancy $(n, \%)$} \\
\hline Bottle & 71 & $15 \cdot 9$ \\
\hline Breast or bottle & 198 & $44 \cdot 2$ \\
\hline Breast & 179 & $40 \cdot 0$ \\
\hline \multicolumn{3}{|l|}{ Maternal smoking $(n, \%)$} \\
\hline Never & 356 & $78 \cdot 8$ \\
\hline Former & 36 & $8 \cdot 0$ \\
\hline Current & 57 & $12 \cdot 6$ \\
\hline \multicolumn{3}{|l|}{ Paternal smoking $(n, \%)$} \\
\hline Never & 224 & $49 \cdot 6$ \\
\hline Former & 52 & $11 \cdot 5$ \\
\hline Current & 176 & 38.9 \\
\hline Maternal history of allergy $(n, \%)^{*}$ & 257 & $56 \cdot 9$ \\
\hline Paternal history of allergy $(n, \%)^{*}$ & 232 & $51 \cdot 3$ \\
\hline Maternal education $>13$ years $(n, \%)$ & 303 & $67 \cdot 0$ \\
\hline
\end{tabular}

Values are presented as number and percentage of the population (values do not add to $100 \%$ because of missing data) or mean and standard deviation.

${ }^{*}$ Allergy comprises asthma, atopic eczema, nasal allergy, pollinosis and food allergy.

statistical software package version $9 \cdot 1$. Significance was defined as two-sided $P<0 \cdot 05$.

\section{Results}

Basic characteristics of the pre-school children in the present study are presented in Tables 1 and 2. Among the 452 children, twenty $(8 \cdot 3 \%)$ boys and seventeen $(8 \cdot 0 \%)$ girls were revealed to be asthma cases, according to the criteria for young children based on ATS-DLD. The most common family history of allergy among the participants' parents was pollinosis, and the number of smoking fathers (including current and former smokers) was larger than that of smoking mothers. Fifty-five (12\%) children reported to have had a history of food allergy.

Table 3 presents OR and 95\% CI for the prevalence of asthma for intake of antioxidant vitamins, fruits and vegetables. Intakes of vitamin C and vitamin E were significantly and inversely associated with asthma. Children in the highest tertile of vitamin C intake had a $65 \%$ decreased OR for asthma in the multivariate model, and the trend across nutrient estimates of vitamin $\mathrm{C}$ was statistically significant ( $P$ for trend $=0 \cdot 02)$. The OR $(95 \% \mathrm{CI})$ for children in the highest tertile of vitamin $\mathrm{E}$ intake was $0 \cdot 32(0 \cdot 12,0 \cdot 85)$ in comparison with the reference in the multivariate model,
Table 2 Daily nutrient intakes of the 452 Japanese pre-school children

\begin{tabular}{lcr}
\hline Nutrient & Mean & \multicolumn{1}{c}{ SD } \\
\hline Total energy $(\mathrm{kJ})$ & 5899 & $1105 \cdot 0$ \\
Fruit intake $(\mathrm{g})$ & $91 \cdot 9$ & $76 \cdot 8$ \\
Vegetable intake $(\mathrm{g})$ & $138 \cdot 5$ & $79 \cdot 4$ \\
Retinol $(\mu \mathrm{g})$ & $168 \cdot 2$ & $122 \cdot 1$ \\
$\alpha$-Carotene $(\mu \mathrm{g})$ & $334 \cdot 7$ & $292 \cdot 8$ \\
$\beta$-Carotene $(\mu \mathrm{g})$ & 1704 & $1239 \cdot 0$ \\
Cryptoxanthin $(\mu \mathrm{g})$ & $368 \cdot 9$ & $523 \cdot 8$ \\
Retinol equivalents $(\mu \mathrm{g})$ & $373 \cdot 1$ & $171 \cdot 5$ \\
$\beta$-Carotene equivalents $(\mu \mathrm{g})$ & 2067 & $1407 \cdot 0$ \\
Vitamin C $(\mathrm{mg})$ & $77 \cdot 5$ & $51 \cdot 1$ \\
Vitamin E (mg) & $5 \cdot 09$ & $1 \cdot 6$ \\
Total fatty acids $(\mathrm{g})$ & $41 \cdot 7$ & $11 \cdot 4$ \\
SFA $(\mathrm{g})$ & $15 \cdot 7$ & $5 \cdot 0$ \\
PUFA $(\mathrm{g})$ & $9 \cdot 2$ & $2 \cdot 5$ \\
MUFA (g) & $16 \cdot 7$ & $4 \cdot 8$ \\
$n-3$ PUFA (g) & $1 \cdot 4$ & $0 \cdot 5$ \\
$n-6$ PUFA (g) & $7 \cdot 7$ & $2 \cdot 2$ \\
EPA (mg) & $95 \cdot 4$ & $96 \cdot 9$ \\
DHA (mg) & 196 & $159 \cdot 1$ \\
Arachidonic acid $(\mathrm{mg})$ & $113 \cdot 9$ & $43 \cdot 1$ \\
Linoleic acid $(18: 2 n-6)(\mathrm{mg})$ & 7529 & $2114 \cdot 0$ \\
$\alpha$-Linolenic acid $(18: 3 n-3)(\mathrm{mg})$ & 1084 & $352 \cdot 9$ \\
\hline
\end{tabular}

Values are presented as mean and standard deviation.

with a significant trend ( $P$ for trend $=0 \cdot 008$ ). Forty-two children were taking vitamin supplements. The associations between asthma and intakes of vitamins $\mathrm{C}$ and $\mathrm{E}$ from dietary sources only did not alter the results. There were no significant associations with other antioxidant vitamins, fruit and vegetables.

We found no significant associations of intakes of fatty acids, fish and meat, as a source of fatty acids, with asthma. The OR $(95 \% \mathrm{CI})$ of asthma was $1.93(0 \cdot 80,4 \cdot 66)$ for the highest tertile of $n-6$ PUFA: $n$ - 3 PUFA and $0 \cdot 57(0 \cdot 23,1 \cdot 40)$ for the highest tertile of very-long-chain $n-3$ PUFA from fish (EPA plus DHA). The trends for these associations were not significant. Exclusion of children with a history of food allergy or food avoidance from the analysis did not change the results substantially.

\section{Discussion}

We found that asthma was significantly associated with low intakes of vitamin $\mathrm{C}$ and vitamin $\mathrm{E}$ as antioxidant nutrients in Japanese pre-school children. Intake of any type of fatty acids was not associated with the status of asthma in this analysis.

Airways in asthmatic subjects have specific inflammatory abnormalities related to increased generation of reactive oxygen species and the tissue damage by free radicals ${ }^{(32)}$. Dietary antioxidant vitamins such as vitamins A, C and E may protect the respiratory system from oxidants. So far, two case-control studies and three cross-sectional studies have been conducted to examine the association between childhood asthma and intake of antioxidant vitamins. Significant inverse associations were observed in some, but 
Table 3 Odds ratios and $95 \%$ confidence intervals of prevalence of childhood asthma according to tertile of daily antioxidant vitamin intake among 452 Japanese pre-school children

\begin{tabular}{|c|c|c|c|c|c|c|c|c|c|}
\hline & \multirow{2}{*}{$\begin{array}{l}\text { No. of } \\
\text { cases }\end{array}$} & \multirow{2}{*}{$\begin{array}{c}\text { No. of } \\
\text { participants }\end{array}$} & \multirow{2}{*}{$\begin{array}{c}\text { Prevalence } \\
(\%)\end{array}$} & \multicolumn{2}{|r|}{ Crude } & \multicolumn{2}{|c|}{ Age- and sex-adjusted } & \multicolumn{2}{|c|}{ Multivariate-adjusted ${ }^{\star}$} \\
\hline & & & & OR & $95 \% \mathrm{Cl}$ & OR & $95 \% \mathrm{Cl}$ & OR & $95 \% \mathrm{Cl}$ \\
\hline \multicolumn{10}{|l|}{ Vitamin $A(\mu \mathrm{g}) \dagger$} \\
\hline 1 (lowest) & 15 & 151 & $9 \cdot 9$ & 1.00 & Ref. & $1 \cdot 00$ & Ref. & 1.00 & Ref. \\
\hline 2 & 11 & 151 & $7 \cdot 3$ & $0 \cdot 71$ & $0 \cdot 32,1 \cdot 61$ & $0 \cdot 71$ & $0 \cdot 32,1 \cdot 61$ & $0 \cdot 71$ & $0 \cdot 30,1 \cdot 70$ \\
\hline $\begin{array}{l}3 \text { (highest) } \\
P \text { for trend } \neq\end{array}$ & 11 & 150 & $7 \cdot 3$ & & $\begin{array}{l}0.32,1 \cdot 62 \\
0.66\end{array}$ & \multicolumn{2}{|r|}{0.68} & \multicolumn{2}{|r|}{0.66} \\
\hline \multicolumn{10}{|l|}{$\alpha$-Carotene $(\mu \mathrm{g})$} \\
\hline 1 (lowest) & 10 & 151 & $6 \cdot 6$ & $1 \cdot 00$ & Ref. & $1 \cdot 00$ & Ref. & $1 \cdot 00$ & Ref. \\
\hline 2 & 14 & 151 & $9 \cdot 3$ & $1 \cdot 44$ & $0 \cdot 62,3 \cdot 35$ & $1 \cdot 43$ & $0 \cdot 61,3 \cdot 35$ & $1 \cdot 53$ & $0 \cdot 64,3 \cdot 68$ \\
\hline $\begin{array}{l}3 \text { (highest) } \\
P \text { for trend } \neq\end{array}$ & 13 & 150 & $8 \cdot 7$ & & $\begin{array}{l}0.57,3 \cdot 15 \\
0.6\end{array}$ & & $\begin{array}{l}0.57,3 \cdot 15 \\
0.66\end{array}$ & \multicolumn{2}{|r|}{0.70} \\
\hline \multicolumn{10}{|l|}{$\beta$-Carotene $(\mu \mathrm{g})$} \\
\hline 1 (lowest) & 13 & 151 & $8 \cdot 6$ & $1 \cdot 00$ & Ref. & $1 \cdot 00$ & Ref. & $1 \cdot 00$ & Ref. \\
\hline 2 & 15 & 151 & $9 \cdot 9$ & $1 \cdot 17$ & $0.54,2.59$ & $1 \cdot 17$ & $0.54,2.59$ & $1 \cdot 14$ & $0.50,2 \cdot 63$ \\
\hline $\begin{array}{l}3 \text { (highest) } \\
P \text { for trend } \neq\end{array}$ & 9 & 150 & $6 \cdot 0$ & $0 \cdot 68$ & $\begin{array}{l}0.27,1.62 \\
0.53\end{array}$ & $0 \cdot 68$ & $\begin{array}{l}0.27,1.62 \\
0.52\end{array}$ & $0 \cdot 65$ & $\begin{array}{l}0.26,1.62 \\
0.46\end{array}$ \\
\hline \multicolumn{10}{|l|}{ Cryptoxanthin $(\mu \mathrm{g})$} \\
\hline 1 (lowest) & 17 & 151 & $11 \cdot 3$ & $1 \cdot 00$ & Ref. & $1 \cdot 00$ & Ref. & $1 \cdot 00$ & Ref. \\
\hline 2 & 11 & 151 & $7 \cdot 3$ & 0.62 & $0 \cdot 28,1 \cdot 37$ & 0.62 & $0 \cdot 28,1 \cdot 37$ & 0.67 & $0 \cdot 25,1 \cdot 33$ \\
\hline 3 (highest) & 9 & 150 & $6 \cdot 0$ & 0.50 & $0 \cdot 22,1 \cdot 17$ & 0.50 & $0 \cdot 22,1 \cdot 17$ & 0.49 & $0 \cdot 21,1 \cdot 18$ \\
\hline$P$ for trend $\ddagger$ & & & & & $0 \cdot 11$ & & $0 \cdot 11$ & & 0.11 \\
\hline \multicolumn{10}{|l|}{ Vitamin C (mg) } \\
\hline 1 (lowest) & 15 & 151 & $12 \cdot 6$ & $1 \cdot 00$ & Ref. & $1 \cdot 00$ & Ref. & $1 \cdot 00$ & Ref. \\
\hline 2 & 11 & 151 & $7 \cdot 3$ & 0.55 & $0 \cdot 25,1 \cdot 12$ & 0.54 & $0 \cdot 25,1 \cdot 18$ & 0.58 & $0.25,1 \cdot 34$ \\
\hline 3 (highest) & 7 & 150 & $4 \cdot 7$ & 0.34 & $0 \cdot 14,0 \cdot 84$ & 0.34 & $0 \cdot 14,0.83$ & 0.35 & $0.14,0.88$ \\
\hline$P$ for trend $\ddagger$ & & & & & 0.01 & & 0.01 & & 0.02 \\
\hline \multicolumn{10}{|l|}{ Vitamin $E(\mathrm{mg})$} \\
\hline 1 (lowest) & 17 & 151 & $11 \cdot 3$ & 1.00 & Ref. & $1 \cdot 00$ & Ref. & 1.00 & Ref. \\
\hline 2 & 14 & 151 & $9 \cdot 3$ & $0 \cdot 81$ & $0 \cdot 38,1 \cdot 70$ & $0 \cdot 80$ & $0 \cdot 38,1 \cdot 70$ & 0.68 & $0.31,1.48$ \\
\hline 3 (highest) & 6 & 150 & $4 \cdot 0$ & 0.33 & $0.13,0.86$ & 0.33 & $0.13,0.86$ & 0.32 & $0.12,0.85$ \\
\hline$P$ for trend $\ddagger$ & & & & & 0.013 & & 0.013 & & 0.008 \\
\hline \multicolumn{10}{|l|}{ Fruit $(\mathrm{g})$} \\
\hline 1 (lowest) & 15 & 151 & $10 \cdot 5$ & 1.00 & Ref. & 1.00 & Ref. & 1.00 & Ref. \\
\hline 2 & 10 & 151 & $6 \cdot 6$ & $0 \cdot 61$ & $0 \cdot 26,1 \cdot 40$ & $0 \cdot 60$ & $0 \cdot 26,1 \cdot 38$ & 0.57 & $0.24,1.36$ \\
\hline 3 (highest) & 10 & 150 & 6.7 & 0.61 & $0.26,1.41$ & 0.59 & $0.25,1.38$ & 0.61 & $0.26,1.48$ \\
\hline$P$ for trend $\ddagger$ & & & & & 0.11 & & $0 \cdot 11$ & & 0.11 \\
\hline \multicolumn{10}{|l|}{ Vegetables (g) } \\
\hline 1 (lowest) & 13 & 151 & $8 \cdot 6$ & 1.00 & Ref. & $1 \cdot 00$ & Ref. & 1.00 & Ref. \\
\hline 2 & 15 & 151 & $9 \cdot 9$ & $1 \cdot 17$ & $0.54,2 \cdot 55$ & $1 \cdot 16$ & $0.53,2.55$ & 1.05 & $0.46,2.40$ \\
\hline 3 (highest) & 9 & 150 & 6.0 & 0.68 & $0.28,1.64$ & 0.67 & $0.28,1.63$ & 0.51 & $0.20,1.32$ \\
\hline$P$ for trend $\ddagger$ & & & & & 0.40 & & 0.38 & & 0.19 \\
\hline
\end{tabular}

Ref, referent category.

*Adjusted for child's age, child's sex, child's BMI, breast-feeding, child's history of food allergy, mother's age, parental history of allergy, maternal education level, the number of siblings and household smoking.

+ Vitamin $A(\mu \mathrm{g})=$ retinol $(\mu \mathrm{g})+1 / 12 \beta$-carotene $(\mu \mathrm{g})+1 / 24 \alpha$-carotene $(\mu \mathrm{g})+1 / 24$ cryptoxanthin $(\mu \mathrm{g})$.

$\ddagger P$ for trend across continuous values of each nutrient.

not all, of the studies ${ }^{(10-14)}$. Hijazi et al. reported increased OR of asthma for low intakes of vitamins $\mathrm{C}$ and $\mathrm{E}$, as evaluated by FFQ, among asthmatic children aged 12 years compared with non-asthmatic controls in Saudi Arabia ${ }^{(10)}$. However, another case-control study reported no differences in FFQ reports of antioxidant intake between wheezing and non-wheezing children in the $\mathrm{UK}^{(11)}$. Among three cross-sectional studies, one revealed that teenagers in the USA who had a lower intake of vitamin $\mathrm{E}$ but not of vitamin $C$ as derived from FFQ results had significantly increased OR for asthma ${ }^{(12)}$. Two other studies adopted the $24 \mathrm{~h}$ dietary recall and reported that a limited intake of vitamin C was associated with elevated OR for asthma among children in Taiwan and the USA, although neither study obtained statistical significance ${ }^{(13,14)}$.
Fruit and vegetables are sources of antioxidant vitamins. Previous authors have reported fruit and vegetables to be associated with decreased risk of asthma in some $e^{(12,15-19)}$ but not other epidemiological studies ${ }^{(20,21)}$. However, we failed to find a significant inverse association between asthma and fruit and vegetable intake. Compounds other than vitamins $\mathrm{C}$ and $\mathrm{E}$ in fruit and vegetables may be partially responsible for the lack of significant associations. Recently, folic acid supplementation during pregnancy has been reported to increase the risk of children's asthma and wheezing ${ }^{(33)}$.

We did not observe significant associations of any type of fatty acids, fish and meat with asthma in the present study. Some previous studies have revealed positive associations between asthma and intake of fatty acids, 
such as PUFA ${ }^{(11,22,24-26)}, n-6$ fatty acids ${ }^{(24)}$ and linoleic $\operatorname{acid}^{(24)}$. However, for each subtype of fatty acids, the results among these studies are inconsistent. Thus, a recent review concluded that the body of observational evidence between PUFA and asthma is weak ${ }^{(34)}$.

Limitations of the present study should be considered. In interpreting our results, we should remember that we conducted multiple testing and so some findings could be by chance. The number of participants could be too small to detect associations. The lack of a significant association of intake of fruit and vegetable with asthma in the present study might have been due to insufficient statistical power. Given that the size of our study population was 452, we had power of $23 \%$ to detect an OR of $0 \cdot 61$, which was observed for the association between asthma and fruit intake at the two-sided 5\% significance level. Among five previously cited articles regarding childhood asthma and antioxidant nutrients, the case-control studies were composed of a small number of children, the smallest including twentythree cases and twenty-three controls ${ }^{(10,11)}$. The remaining three cross-sectional studies were conducted based on the data from over 1000 participants ${ }^{(12-14)}$. We collected only parent-reported information on asthma symptoms but no data from medical tests, such as bronchial hyperresponsiveness. However, analysis of the information on symptoms derived from the questionnaire was apparently sufficient because bronchial hyper-responsiveness has been shown to have lower sensitivity in relation to asthma than a questionnaire about symptoms $(0 \cdot 47$ for bronchial hyperresponsiveness and $0 \cdot 70$ for symptoms $)^{(35)}$. The definition of asthma is also important and appears to vary among the studies cited above. Some studies identified cases by asking about wheezing only ${ }^{(14,16,26)}$, and another simply defined cases as those with a prior diagnosis of asthma ${ }^{(22)}$. We adopted a standardized and validated ATS-DLD questionnaire for children ${ }^{(36)}$, which should have reduced the misclassification of asthma. The cross-sectional design of the present study was also a disadvantage. We cannot demonstrate a causal inference between dietary intake of nutrients and the prevalence of asthma. Although exclusion of children who reported to have avoided certain foods did not alter the results, it is possible that early symptoms of asthma might have changed eating habits, which resulted in lower intakes of vitamins $\mathrm{C}$ and $\mathrm{E}$.

Any dietary assessment method is subject to measurement error. In addition, it seems difficult to assess the dietary habits of pre-school children, because they often eat small amounts of food, cannot adequately report their intake by themselves and often receive care from others $^{(37)}$. It is unlikely that parents are always good surrogate reporters of their children's diet in practice ${ }^{(38)}$. We estimated the children's diet from the records kept primarily by mothers. In addition to the food records, we obtained an estimate of school lunch intake by measuring the leftovers with the help of dietitians. All of the abovecited studies used an $\mathrm{FFQ}^{(10-12,18,19,21,23,24)}$ or dietary recall instrument administered to mothers ${ }^{(13,14,22)}$. In addition, some studies included a limited number of food items in the FFQ. However, we keep it in mind that the number of repetitions in the dietary records was too low to estimate the usual dietary habits of the children.

\section{Conclusions}

Our findings support the hypothesis that higher dietary intakes of vitamins $\mathrm{C}$ and $\mathrm{E}$ are associated with a reduced risk of childhood asthma. To elucidate the association between antioxidant vitamins as well as other nutrients and the occurrence of childhood asthma, larger studies with a prospective design are necessary.

\section{Acknowledgements}

Source of funding: The present study was supported in part by a grant from the Ministry of Education, Culture, Sports, Science, and Technology, Japan. Conflicts of interest: All authors declare that they have no conflict of interest. Authors' contribution: C.N., K.A. and K.N. designed the study. K.N., Y.S., K. Watanabe, S.O., K.A. and C.N. designed the study, conducted the field work and collected the data. K.N., K. Wada, Y.T. and M.T. conducted the statistical analysis. All authors interpreted the results of analysis. K.N. and C.N. made the draft of the manuscript. K. Wada, Y.T. and M.T. were responsible for critical revision of the manuscript. All authors read and approved the final manuscript. Acknowledgements: The authors are very grateful to the preschool children's families who participated in this study. They also appreciate the staff of the pre-schools for their cooperation.

\section{References}

1. Nishimurota T, Nishima S, Morikawa A et al. (2008) Japanese Pediatric Guideline for the Treatment and Management of Asthma. Tokyo: Kyowa Kikaku.

2. Wong GW \& Chow CM (2008) Childhood asthma epidemiology: insights from comparative studies of rural and urban populations. Pediatr Pulmunol 43, 107-116.

3. Devereux G \& Seaton A (2005) Diet as a risk factor for atopy and asthma. J Allergy Clin Immunol 115, 1109-1117.

4. von Mutius E (1998) The rising trends in asthma and allergic disease. Clin Exp Allergy 28, Suppl. 5, S45-S49.

5. von Mutius E, Weiland SK, Fritzsch C et al. (1998) Increasing prevalence of hay fever and atopy among children in Leipzig, East Germany. Lancet 351, 862-866.

6. Black PN \& Sharpe S (1997) Dietary fat and asthma: is there a connection? Eur Respir J 10, 6-12.

7. James MJ, Gibson RA \& Cleland LG (2000) Dietary polyunsaturated fatty acids and inflammatory mediator production. Am J Clin Nutr 71, 1 Suppl., 343S-348S.

8. Caramori G \& Papi A (2004) Oxidants and asthma. Thorax 59, $170-173$.

9. MacNee W (2001) Oxidative stress and lung inflammation in airways disease. Eur J Pharmacol 429, 195-207. 
10. Hijazi N, Abalkhail B \& Seaton A (2000) Diet and childhood asthma in a society in transition: a study in urban and rural Saudi Arabia. Thorax 55, 775-779.

11. Murray CS, Simpson B, Kerry G et al. (2006) Dietary intake in sensitized children with recurrent wheeze and healthy controls: a nested case-control study. Allergy 61, 438-442.

12. Burns JS, Dockery DW, Neas LM et al. (2007) Low dietary nutrient intakes and respiratory health in adolescents. Chest 132, 238-245.

13. Huang SL \& Pan WH (2001) Dietary fats and asthma in teenagers: analysis of the first Nutrition and Health Survey in Taiwan (NAHSIT). Clin Exp Allergy 31, 1875-1880.

14. Romieu I, Mannino DM, Redd SC et al. (2004) Dietary intake, physical activity, body mass index, and childhood asthma in the Third National Health And Nutrition Survey (NHANES III). Pediatr Pulmonol 38, 31-42.

15. Njå F, Nystad W, Lødrup Carlsen KC et al. (2005) Effects of early intake of fruit or vegetables in relation to later asthma and allergic sensitization in school-age children. Acta Paediatr 94, 147-154.

16. Forastiere F, Pistelli R, Sestini P et al. (2000) Consumption of fresh fruit rich in vitamin $\mathrm{C}$ and wheezing symptoms in children. SIDRIA Collaborative Group, Italy (Italian Studies on Respiratory Disorders in Children and the Environment). Thorax 55, 283-288.

17. Nagel G, Weinmayr G, Kleiner A et al. (2010) Effect of diet on asthma and allergic sensitisation in the International Study on Allergies and Asthma in Childhood (ISAAC) Phase Two. Thorax 65, 516-522.

18. Tabak C, Wijga AH, de Meer G et al. (2006) Diet and asthma in Dutch school children (ISAAC-2). Thorax 61, 1048-1053.

19. Chatzi L, Torrent M, Romieu I et al. (2007) Diet, wheeze, and atopy in school children in Menorca, Spain. J Pediatr Allergy Immunol 18, 480-485.

20. Lewis SA, Antoniak M, Venn AJ et al. (2005) Secondhand smoke, dietary fruit intake, road traffic exposures, and the prevalence of asthma: a cross-sectional study in young children. Am J Epidemiol 161, 406-411.

21. Chatzi L, Apostolaki G, Bibakis I et al. (2007) Protective effect of fruits, vegetables and the Mediterranean diet on asthma and allergies among children in Crete. Thorax 62, 677-683.

22. Dunder T, Kuikka L, Turtinen J et al. (2001) Diet, serum fatty acids, and atopic diseases in childhood. Allergy 56, 425-428.

23. Oddy WH, de Klerk NH, Kendall GE et al. (2004) Ratio of omega- 6 to omega- 3 fatty acids and childhood asthma. J Asthma 41, 319-326.

24. Miyake Y, Sasaki S, Arakawa M et al. (2008) Fatty acid intake and asthma symptoms in Japanese children: the Ryukyus Child Health Study. Clin Exp Allergy 38, 1644-1650.
25. Haby MM, Peat JK, Marks GB et al. (2001) Asthma in preschool children: prevalence and risk factors. Thorax $\mathbf{5 6}$, 589-595.

26. Bolte G, Frye C, Hoelscher B et al. (2001) Margarine consumption and allergy in children. Am J Respir Crit Care Med 163, 277-279.

27. Nurmatov U, Devereux G \& Sheikh A (2011) Nutrients and foods for the primary prevention of asthma and allergy: systematic review and meta-analysis. $J$ Allergy Clin Immunol 127, 724-733.e1-30.

28. Ferris BG Jr (1978) Epidemiology Standardization Project (American Thoracic Society). Recommended respiratory disease questionnaires for use with adults and children in epidemiological research. Am Rev Respir Dis 118, 6 Pt 2, $7-53$.

29. Buzzard M (1998) 24-hour dietary recall and food record methods. In Nutritional Epidemiology, 2nd ed., pp. 50-73 [W Willett, editor]. New York: Oxford University Press.

30. Sasaki S, Kobayashi M \& Tsugane S (1999) Development of substituted fatty acid composition table for the use in nutritional epidemiologic studies for Japanese populations: its methodological backgrounds and the evaluation. J Epidemiol 9, 190-207.

31. Willett W \& Stampfer M (1998) Implication of total energy intake for epidemiological analysis. In Nutritional Epidemiology, 2nd ed., pp. 273-301 [W Willett, editor]. New York: Oxford University Press.

32. Riccioni G, Barbara M, Bucciarelli $\mathrm{T}$ et al. (2007) Antioxidant vitamin supplementation in asthma. Ann Clin Lab Sci 37, 96-101.

33. Ownby DR (2009) Has mandatory folic acid supplementation of foods increased the risk of asthma and allergic disease? J Allergy Clin Immunol 123, 1260-1261.

34. Allan K \& Devereux G (2011) Diet and asthma: nutrition implications from prevention to treatment. J Am Diet Assoc 111, 258-268.

35. Remes ST, Pekkanen J, Remes K et al. (2002) In search of childhood asthma: questionnaire, tests of bronchial hyperresponsiveness, and clinical evaluation. Thorax 57, 120-126.

36. Torén K, Brisman J \& Järvholm B (1993) Asthma and asthma-like symptoms in adults assessed by questionnaires. A literature review. Chest 104, 600-608.

37. Stein AD, Shea S, Basch CE et al. (1992) Consistency of the Willett semiquantitative food frequency questionnaire and 24-hour dietary recalls in estimating nutrient intakes of preschool children. Am J Epidemiol 35, 667-677.

38. Livingstone MB, Robson PJ \& Wallace JM (2004) Issues in dietary intake assessment of children and adolescents. BrJ Nutr 92, Suppl. 2, S213-S222. 